\title{
A ordem da roupa em Foucault: as relações de poder presentes no discurso midiático do corpo adornado
}

\author{
El ordem de la ropa en Foucault: las relaciones de poder presentes em el \\ discurso mediático del cuerpo adornado
}

\section{The order of clothing in Foucault: the relations of power present in the mediatic discourse of the adorned body}

\author{
Baga de Bagaceira Souza Campos ${ }^{1}$ \\ Renata Pitombo Cidreira ${ }^{2}$
}

\begin{abstract}
Resumo
Este artigo visa compreender a roupa, entendendo seu papel midiático, enquanto potência discursiva nas relações de poder que se estabelecem no campo social. Trata-se, aqui, de apreender as discussões propostas por Michel Foucault em seu texto $A$ ordem do discurso, proferido em sua aula inaugural na Collège de France, datada de dois de dezembro de 1970, e desenvolvê-las a partir de uma perspectiva contra-hegemônica para pensar a vestimenta em seu status comunicativo e revelador das relações sociais. Serão destacados os procedimentos internos, externos e de funcionamento, abordados por Foucault em sua análise sobre o discurso, alocando as vestes em pleno diálogo com o campo de poder. Aqui, serão evidenciados os corpos em suas dissidências sexuais e de gênero, enquanto sujeitos levados à marginalização, a partir das definições de controle elencadas pelo autor. Nesta pesquisa, evidenciamos os estudos da Comunicação na abordagem sobre as camadas disciplinatórias que regem o campo das vestes nos sujeitos que destoam dos gêneros e sexualidades ideais.
\end{abstract}

Palavras-Chave: Discurso; Michel Foucault; Mídia; Poder; Vestes.

\section{Resumen}

Esta ponencia tiene por objeto comprender la ropa, entendiendo su papel mediático, como potencia discursiva en las relaciones de poder que se establecen en el campo social. Se trata, aquí, de aprehender las discusiones propuestas por Michel Foucault en su texto El orden del discurso, pronunciado en su clase inaugural en la Collège de France, fechada el 2 de diciembre de 1970, y desarrollarlas desde una perspectiva contrahegemónica para pensar la vestimenta en su estado comunicativo y revelador de las relaciones sociales. Se destacarán los procedimientos internos, externos y de funcionamiento, abordados por Foucault en su análisis sobre el discurso, asignando las vestiduras en pleno diálogo con el campo de poder. Aquí, se evidenciarán los cuerpos en sus disidencias sexuales y de género, en cuanto sujetos llevados a la marginación, a partir de las definiciones de control enumeradas por el autor. En esta investigación, evidenciamos los estudios de la Comunicación en el abordaje sobre las capas disciplinatorias que rigen el campo de las vestiduras en los sujetos que desto de los géneros y sexualidades ideales.

\footnotetext{
${ }^{1}$ Mestrando do Programa de Pós-graduação em Comunicação da Universidade Federal do Recôncavo da Bahia. Bacharel em Comunicação Social - Jornalismo pela mesma Instituição; Cachoeira, Bahia, Brasil; bagadebagaceira1992@gmail.com.

2 Jornalista, Doutora em Comunicação e Cultura Contemporâneas (FACOM/UFBA), professora adjunta da Universidade Federal do Recôncavo da Bahia (UFRB); Cachoeira, Bahia, Brasil; pitombo@yahoo.com.
} 
Palabras claves: Discurso; Michel Foucault; Medios de Comunicación; Poder; Ropa.

\begin{abstract}
This article aims to understand clothing, understanding its mediatic role, as a discursive power in the relations of power that are established in the social field. It is, here, to apprehend the discussions proposed by Michel Foucault in his text The order of the speech, delivered in his inaugural lecture at the Collège de France, dated December 2, 1970, and develop them from a counter-hegemonic perspective to think of clothing in its communicative and revealing status of social relations. Internal, external and operational procedures, addressed by Foucault in his analysis of the discourse, will be highlighted, allocating the clothes in full dialogue with the field of power. Here, the bodies will be evidenced in their sexual and gender disagreements, as subjects led to marginalization, from the definitions of control listed by the author. In this research, we highlight the studies of Communication in the approach on the disciplinary layers that govern the field of dress in the subjects that disclose the genders and sexualities ideals.
\end{abstract}

Keywords: Discourse; Michel Foucault; Media; Power; Clothes.

\title{
1. Introdução
}

Começaremos este artigo com o objetivo de despertar no texto A ordem do discurso (FOUCAULT, 2012) uma abordagem a partir da perspectiva da roupa enquanto um discurso midiático, que a respeito da sua intensa relação com o corpo na formação da composição da aparência (CIDREIRA, 2005), é demarcada, também, pelas intensas relações de poder. Nesse sentido, o discurso do adorno enquanto "comunicação não-verbal" (MCLUHAN, 2005, p. 141) reverbera sobre os corpos dissidentes do gênero e da sexualidade, chamados também de queers ${ }^{3}$, enquanto fator expressivo de suas sensibilidades adornadas.

As seções que se apresentam neste trabalho seguem o nexo sequencial das subdivisões propostas pelas contribuições de Michel Foucault (2012) em sua obra sobre o discurso. Entre elas destacam-se os procedimentos internos, externos do discurso e os procedimentos para o seu funcionamento. Assim, podemos pensar de forma análoga, a partir das observações de Foucault em uma ordem das roupas, como se tornará potente o discurso que executam as operações sobre as disciplinas, as ordens e as leis de uma política que invisibiliza determinados sujeitos, observando as suas condições sexuais e de gênero, com base na lógica de legitimação do saber e do poder.

Pensarmos sobre como as ordens disciplinadoras lançadas sobre a roupa funcionam na nossa comparação foucaultiana, serve para refletirmos sobre as organizações de força sobre o corpo do sujeito adornado que não controla mais o seu corpo, mas sim é, de antemão, já

\footnotetext{
${ }^{3} \mathrm{O}$ termo queer pode ser traduzido por estranho, talvez ridículo, excêntrico, raro, extraordinário. Definição postulada por Guacira Lopes Louro. Ver sua publicação: LOURO, Guacira Lopes. Um corpo estranho: ensaios sobre sexualidade e teoria queer. $2^{\mathrm{a}}$ ed. Belo Horizonte: Autêntica, 2008. p. 38.
} 
controlado pelo sistema do vestuário e sua comunicabilidade é incidida sobre as demandas de operações controladoras. Afinal de contas, como nos afirma Foucault (2012, p. 8), “onde está o perigo nas pessoas que proliferam o seu discurso?", ao que acrescentaríamos: onde está o risco, aos grupos subalternizados, em adornar-se?

Desse modo, os embates impulsionados pela vestimenta nos corpos queers, na produção do diferente, do anormal, do estranho, operam sobre os processos disciplinatórios que os tornam combatíveis dentro dessa lógica de exclusão. Portanto, convidamos vocês para refletirmos juntos sobre o papel da vestimenta na sociedade, não como algo sem importância, mas sim para compreendermos as operações que visam normativizar nossos corpos adornados dentro de uma "verdade".

\section{Os princípios externos sobre a ordem da roupa}

Entre os procedimentos ou princípios de exclusão incorporados na sociedade e que se exercem de modo exterior e colocam o poder e o desejo como fundamentos para sua valorização, está o da interdição. Nela, podemos associar a palavra proibida a ideia, também, de roupa proibida. Como determinar os modos com os quais devemos nos adornar? E a quais vestimentas seremos submetidos? Elas devem corresponder "as exigências funcionais do discurso que deve produzir sua verdade" (FOUCAULT, 1999, p. 67), no sentido de legitimar o cumprimento as submetidas regras destinadas a cada corpo, a cada performance de gênero, sexualidade e comportamento.

$\mathrm{O}$ ato de vestir, segundo Renata Pitombo Cidreira perpassa para além da questão de apenas cobrir o corpo (CIDREIRA, 2005). Para a autora, "nada mais arraigado em nossa própria cultura do que o 'ato de vestir' o corpo e, no entanto, sequer damos muita atenção ao que o vestuário nos impõe e propicia" (CIDREIRA, 2005, p.13). Entendendo a sua importância na formação da aparência, a potencialidade do próprio vestir, enquanto ato de reafirmação de alguns sujeitos concebidos como excluídos, é encarada como forma de sentir e perceber as suas próprias sensibilidades, reapropriando-a enquanto ferramenta de luta e de afirmação de suas identidades dissidentes.

Em outro princípio de exclusão, Michel Foucault vai tratar de apresentar a separação e a rejeição. Quando o autor nos interpela sobre a loucura enquanto um discurso rejeitado, pela oposição à razão e pelos exercícios de poder que os colocam à margem, nos faz refletir sobre a possibilidade do poder exercido no modo como nos adornamos. Assim, "basta pensar em 
tudo isto para supor que a separação, longe de estar apagada, se exerce de outro modo, segundo linhas distintas, por meio de novas instituições e com efeitos que não são de modo algum os mesmos" (FOUCAULT, 2012, p. 12). A roupa torna-se, portanto, um instrumento que desvela a separação entre os gêneros e reafirma o lugar das performances dissidentes da sexualidade e do gênero e lhe impõem um lugar de subjetivação.

A oposição entre o que é verdadeiro e falso, ainda que arriscada para Foucault, é desenvolvida para pensarmos em como as instituições regulamentam toda essa nuvem que ronda nossas cabeças e já nos afirmam sobre o que é verdade e o que não o é, com o propósito de sempre reconduzir o sujeito da anormalidade em sua plena convicção de falso. O que dizer, por exemplo, sobre o corpo da travesti que traja roupas em desconformidade com o gênero que lhe foi designado ao nascimento (ou até mesmo antes dele)? Ou a bicha afeminada que traja roupas ditas feminilizadas, na contramão do que o sistema dita para os gêneros, masculino ou feminino, em termos de composição da aparência? É importante salientar que as formas verdadeiras sobre como devemos autoplasmar nossos corpos, perpasse sobre as designações ideais tanto dos gêneros quanto das sexualidades apontadas.

Segundo Foucault, não há como negligenciar essa vontade de verdade enquanto forma de "excluir todos aqueles que, ponto por ponto, em nossa história, procuraram contornar essa vontade de verdade e recolocá-la em questão contra a verdade, lá justamente onde a verdade assume a tarefa de justificar a interdição e definir a loucura" (FOUCAULT, 2012, p. 20). Essa verdade é, por muitas vezes, uma vigilância que visa naturalizar algumas questões em detrimento da "demonização" de outras.

Estendendo a nossa reflexão sobre a vestimenta, impetramos os conceitos abordados por Marshall McLuhan (2005, p. 140) na definição das vestes como uma "segunda pele". E, se a roupa é essa extensão do corpo, da pele, ou até mesmo de nossa alma, a vestimenta se mostra em sua capacidade afetiva de relações com os paralelos cerceados pelos dispositivos reguladores do poder. As roupas são sentidas, em nossa análise, a partir de sua compreensão enquanto "um manifesto não-verbal de subversão política" (MCLUHAN, 2005, p. 142).

\section{Os procedimentos internos e as mil e uma roupas}

Entre os procedimentos internos destacados por Michel Foucault (2012), estão o comentário, o autor e a disciplina. A partir deles, Foucault nos ajuda a pensar em modos para refletir os arranjos controladores sobre nossos corpos adornados em suas mil e uma 
possibilidades de adornar-se. Mil e uma possibilidades de roupas? Feitas para quem? Nós somos autorizados a usar o que desejamos?

O comentário funciona para nossa análise da vestimenta, porque estão "além de sua formulação, são ditos, permanecem ditos e estão ainda por dizer" (FOUCAULT, 2012, p. 21, destaque do autor), num diálogo que projeta as combinações vestuárias esperadas sobre os corpos masculinos e femininos. São os discursos que remontam e retomam o jogo narrativo sobre as determinações do indivíduo e, consequentemente, sobre o que ele ou ela irá vestir, utilizar como adereço ou a forma como irá se comportar. O comentário serve, segundo o autor, para compreender o que estava silenciado no primeiro texto; serviria, vamos dizer, como uma voz da narrativa contra-hegemônica, em nossa analogia ao texto do autor, sinalizando novas formulações não presentes no ideal primeiro.

A noção de autor é desenvolvida, aqui, pegando o gancho de Foucault (2012), como forma de colocá-lo sobre uma posição que o permite transformar a obra. E a essa transformação, podemos impetrar as diversas formas que a roupa permite ao corpo. São defendidos os modos de adornar-se, objetivando as suas mil e uma possibilidades, sem a restrição dos gêneros, com o foco nesse processo transformador e transgressor nos modos de uso da roupa.

$\mathrm{Na}$ maneira de pensar as disciplinas tomamos como foco o seu pensamento sobre a constituição das verdades dentro de uma obediência, onde suas teratologias serão jogadas para as margens e é preciso que sejam ditas não somente as verdades, mas que estejam dizendo-as "no verdadeiro" (FOUCAULT, 2012, p. 31). Ou seja, a disciplina sendo "um princípio de controle da produção do discurso" a força, obrigatoriamente, a se reatualizar para informar e emprestar seu jogo no verdadeiro (p. 34). A roupa, por exemplo, em dada época, já poderia informar o seu teor binário e enraizado sobre as performances e divisões de gênero, mas nelas estavam incluídas uma não-produção sobre a reiteração que tais práticas manipulavam dentro do discurso sobre os corpos e o modo como adorná-los.

Esse movimento, contestador sobre as formas corretas de vestir, é apontado por àqueles/as, localizados nessas redes fronteiriças de subjugação, como uma das maneiras pelo qual "estilhaçam o conceito de unidade do vestir" (CIDREIRA, 2005, p. 88) e nos apresentam a fuga aos padrões. Mesmo que essa fuga nem sempre seja fácil, tanto pelas reiterações que hora ou outra tendem a aparecer sobre os padrões de vestimenta dos gêneros, tanto quanto as possíveis repulsas e violências que determinada vestimenta no corpo pode gerar ao outro; é 
desse lugar de rompimento que problematizamos, a partir dos modos pelos quais a vestimenta se apresenta enquanto campo de pesquisa dentro, também, desses procedimentos internos e controladores avaliados por Foucault (2012).

\title{
4. As determinações sobre as vestes e o ato de aquendar
}

Segundo Foucault existem os procedimentos que informam sobre os funcionamentos de controle e aos quais nem todos os indivíduos possuem acesso (2012, p. 35). Quais corpos estariam, portanto, autorizados? Os corpos que fogem a regra conforme o seu gênero designado ao nascimento e a performance do mesmo em suas expressões, modos de adornarse, etc. estariam desse modo não autorizados a fala. Denomina-se, portanto, o ritual enquanto procedimento.

O ritual mostra-se enquanto uma instituição de poder, pois define e pré-estabelece as regras a serem seguidas, como por exemplo, o ritual judiciário, que determina aqueles/as que devem ser condenados por não seguirem os trâmites impostos pela normalização do ritual. Aqui, colocamos o ato de aquendar, que na expressão queer significa esconder o órgão genital por baixo da roupa e não deixá-lo a amostra, e inseri-lo dentro de um ritual dos sujeitos não autorizados. Estes mesmos sujeitos, desautorizados, colocam em xeque a própria ideia de fixação dos modos de vestir-se sobre a imposta conformidade dos seus gêneros e sexos.

Segundo Foucault (2012, p. 37):

\begin{abstract}
O ritual define a qualificação que devem possuir os indivíduos que falam (e que, no jogo de um diálogo, da interrogação, da recitação, devem ocupar determinada posição e formular determinado tipo de enunciados); define os gestos, os comportamentos, as circunstâncias, e todo o conjunto de signos que deve acompanhar o discurso; fixa, enfim, a eficácia suposta ou imposta das palavras, seu efeito sobre aqueles aos quais se dirigem, os limites de seu valor de coerção.
\end{abstract}

Outro exemplo de funcionamento do discurso é o das sociedades de discurso, que segundo o autor, ainda que sua prática não seja dada no mesmo modo como em sociedades passadas, ainda hoje se houve falar da "circulação do discurso médico" ou dos que "se apropriam do discurso econômico ou político" (FOUCAULT, 2012, p. 39). Essas sociedades sustentavam-se sobre uma separação sobre aqueles que detinham o poder sobre determinados 
discursos, quase que num jogo entre aparição e segredo no discurso. Nesse jogo, segundo Foucault (2012, p. 39), podemos destacar as doutrinas, que ao contrário das sociedades de discurso, tendiam enquanto objetivo se espalhar, fazendo com que cada vez mais pessoas proferissem determinados discursos enraizados. Podemos citar, por exemplo, sobre o modo como determinadas agências de controle, como a medicina, proferiram em seus discursos sobre a ideia de gênero enquanto uma designação biológica (deixando de lado suas implicações sociais), numa espécie de determinação natural, e que mesmo com os estudos da sociologia este tipo de discurso proferido por esta instituição (com ligação sobre outras agências) ainda se sustenta como discurso verdadeiro.

Tanto na concepção de sexualidade e de gênero, a roupa produzirá uma comunicabilidade que incidirá de maneira transversal a essas inferências. Judith Butler destaca que:

\begin{abstract}
Se o gênero são os significados culturais assumidos pelo corpo sexuado, não se pode dizer que ele decorra, de um sexo desta ou daquela maneira. Levada a seu limite lógico, a distinção sexo/gênero sugere uma descontinuidade radical entre corpos sexuados e gêneros culturalmente construídos. Supondo por um momento a estabilidade do sexo binário, não decorre daí que a construção de "homens" apliquese exclusivamente a corpos masculinos, ou que o termo "mulheres" interprete somente corpos femininos. (BUTLER, 2003, p. 24).
\end{abstract}

Levamos em consideração o ato de aquendar, devido o seu caráter desconstrutivo. Ao mesmo tempo em que o escondemos enquanto ato, desvelamos uma inclinação no discurso que visa não sexualizar os corpos a partir dos genitais, e, consequentemente, não determinar que tipo de roupa deva-se usar a partir do gênero. Fica livre ao corpo adornar-se da maneira que se sente confortável, independente do que lhes impõe enquanto determinação de sexualidade ou performance de gênero.

\title{
5. Considerações finais
}

O trabalho realizado com base no texto de Michel Foucault, A ordem do discurso (2012), compilado com os estudos comunicativos do corpo adornado e os estudos dissidentes do corpo queer, nos apresentaram a potência que a vestimenta possui enquanto sociabilidade midiática e enquanto questão norteadora sobre as relações de poder imposta aos corpos dentro da lógica binária. As abordagens trazidas, na reflexão dos estudos sobre as relações de saber e 
poder no discurso, se evidenciaram de forma potente quando discutimos a roupa e as implicações que regem sobre o modo como devemos nos adornar.

Nosso intuito foi de apontar os poderes exercidos sobre a roupa e as fragilidades encontradas sobre algumas regras e condutas disciplinares que impõem ao nosso corpo ser atravessado ou não. A ordem do discurso pode estar sobre uma comunicação verbal, expressiva, sintomática, mas ela também se situa sobre uma expressão simbólica e/ou concreta do uso da vestimenta.

Esses procedimentos são operacionalizados de modo que o faça respeitar os mecanismos internalizados, externalizados e de funcionamento sobre a lógica dita por diversas agências, entre elas a religião, a medicina e demais instâncias de controle. Quando suas regras são abandonadas, o sujeito torna-se o corpo que destoa e provoca as fronteiras impositivas. Portanto, compreender a vestimenta dentro desse círculo discursivo, é compreendê-la como parte do nosso corpo e das relações que estabelecemos socialmente e que podem fazê-las surgir enquanto desobedientes ao sistema.

\section{Referências}

BUTLER, Judith. Problemas de gênero: Feminismo e subversão da identidade. Rio de Janeiro: Civilização Brasileira, 2003.

CIDREIRA, Renata Pitombo. Os Sentidos da Moda. São Paulo: Annablume, 2005.

FOUCAULT, Michel. História da sexualidade I: a vontade de saber. $13^{\mathrm{a}}$ ed. Rio de Janeiro: Edições Graal, 1999.

FOUCAULT, Michel. A ordem do discurso. 22a ed. São Paulo: Edições Loyola, 2012.

MCLUHAN, Marshall. Os meios de comunicação como extensão do homem. $14^{\mathrm{a}}$ ed. Tradução de Décio Pignatari. São Paulo, Cultrix, 2005. 